Trans/Form/Açlo, Slo Paulo,

11: 1-11, 1988.

\title{
A METAFÍSICA NA CRÍTICA DA RAZÃO PURA*
}

Franklin Leopoldo e SILVA**

RESUMO: O presente artigo discute as relaçóes entre a perspectiva transcendental inscrita na análise Kantiana das Idéias da Razão (principalmente a Idéia de Unidade) e a herança metafísica tradicional. Para tanto ensaia-se uma leitura da $1^{\not}$ parte do Apéndice da Dialética Transcendental à luz da reelaboraçáo critica do temário metaffsico, com especial énfase na noção escolástica de atributo transcendental do Ser.

UNITERMOS: Crfica; metaffsica; transcendental; unidade; Iógica; ontologia.

A presença da Metafísica na Crítica da Razão Pura é, sabemos, bem mais do que o comentário do projeto especulativo falhado que a-história do pensamento lega como tarefa ao filósofo crf́tico, como aparece no Prefácio da $2^{a}$ edição da C.R.P. A metafísica não é tampouco apenas o infatigável pendor da razão, que a faz projetar seus mais altos interesses na região mais obscura e menos segura do conhecimento. Se procurarmos uma forma mais sistemática desta presença, podemos buscá-la na ilustração das respostas inconclusivas do questionamento metafísico, que a Dialética nos oferece. Lá vemos a deconstrução das ilusőes que a razão arquiteta quando, desgarrada da experiência, crê poder guiar-se por uma compatibilidade não fundamentada entre a Lógica e o Real. É o lugar onde se mostra a ordenação viciosa do pensamento isolado em si mesmo, que constrói a sua pseudo-objetividade a partir do distanciamento radical que o fez perder contato com qualquer objeto. É, já se disse muitas vezes, a contrapartida exemplificativa da Analitica Transcendental, na qual se apresentaram dedutivamente as condições de apreensáo objetiva da realidade fenomênica. Vistas portanto as falhas constitutivas das construçōes racionais na Psicologia, na Cosmologia, na Teologia, apreendese criticamente o estatuto das Idéias metafísicas, desmistificando-se a orientaçăo transcendente pela qual a razão crê completar e mesmo fundar o saber adquirido no âmbito da experiência. Ficamos sabendo, então, que a razão não realiza potencial algum de conhecimento quando. se eleva exclusivamente ao plano das idéias, nem estabelece funcamento ou completude em relação ao plano das sínteses do entendimento, pois a sensibilidade como modo de presença da diversidade original é elemento indispensável desta síntese. A metafísica não tem, portanto, papel fundante, pois a ciência não pode ser fundada na não-ciência: esta ruptura da continuidade clássica entre os graus de saber afasta do universo de objetividade os graus de ser que Descartes e Leibniz acreditavam poder atingir quando o pensamento se volta para as

* Este texto consttul uma versåo ligeiramente ampliada de palestra proferida no Departamento de Filosofia da UNESP, por ocasláo da Jomada de Fllosofia, em setembro de 1980.

*- Departamento de Filosofia - Faculdade de Fllosofla, Letras e Ciencias Humanas - USP - 01000 - Sáo Paulo $-\mathrm{SP}$. 
razões inteligiveis do ser sensivel, num processo que faz ascender o trabalho da razão numa única dimensão da ciência.

No entanto, uma vez completada a apresentação da impossibilidade objetiva da metafísica segue-se, no Apêndice da Dialética Transcendental, uma densa exposição que versa exatamente sobre o arcabouço metafísico do conhecimento objetivo, ou seja, sobre determinadas condições não objetivas do conhecimento objetivo. Não se trata apenas de um texto complementar à Dialética, no sentido de esclarecer posições ali tomadas e completar análises efetuadas. Trata-se de um conjunto de afirmações que têm como tema o Sistema do conhecimento objetivo, numa acepção que as análises levadas a cabo na primeira parte da Crítica não autorizam de modo algum. E no entanto isto será feito sem que Kant volte atrás, um milímetro sequer, das conclusões obtidas na Analítica e contraprovadas na Dialética. É este texto complexo e, de alguma maneira, estranho que vamos comentar brevemente, enfocando-o sob o ângulo das relações entre a instância do transcendental e a metafísica.

O primeiro problema que, julgo, deva ser focalizado é o das condições que tornam necessária uma elucidação do estatuto e função das idéias transcendentais, sobretudo depois da demonstração da não objetividade do conhecimento da razão. Ora, esta ausência de objetividade não faz com que as idéias sejam menos naturais à razão do que as categorias ao entendimento (Nota A). As categorias são susceptíveis de um uso legítimo e isto significa que elas são usadas de forma imanente à experiência. No contexto das condições de objetividade, uso legítimo é sinônimo de uso imanente: as idéias não se ligam diretamente à experiência, mas sim ao entendimento, o que significa que não são imanentes à experiência e é precisamente isto que as diferencia dos conceitos puros. No entanto, como as idéias são fundadas "na natureza de nossas faculdades", elas devem, segundo Kant, possuir uma finalidade e um uso legítimo, no sentido precisamente de uso imanente, ou seja, não transcendente. A partir daí, segue-se que descobrirei o uso legítimo das idéias, pois suponho que elas possuem um, se descobrir o uso imanente. A questão que se coloca imediatamente é a que as idéias seriam imanentes e como se configuraria tal imanência, dando-se desde já como suposto que elas não são imanentes à experiência, o que é função privativa das categorias (Nota B).

Diríamos então que, uma vez que as idéias não se relacionam diretamente com nenhum objeto, elas não têm objeto. E isto é correto se entendermos o objeto na esfera do entendimento. Mas Kant diz: "A razão só tem propriamente como objeto o entendimento e seu emprego conforme a um fim". A razão tem portanto um objeto, o próprio entendimento, mais precisamente: "a diversidade dos conceitos" resultado do conhecimento de entendimento. E o que faz propriamente a razão quanto tem por objeto a diversidade dos conceitos do entendimento? Ela "une por idéias a diversidade dos conceitos, propondo uma certa unidade coletiva como meta para os atos do entendimento, o qual, sem isto, se ocuparia apenas de uma unidade distributiva". Há aqui uma relação entre dois tipos de unidade: coletiva e distributiva. Significa, em poucas palavras, que a razão engloba coletivamente (totalmente) aquilo que o entendimento visa distributivamente quando se ocupa dos encadeamentos "pelos quais" as séries empíricas se constituem como tais. Mas, ao fazer isto, a razão se vincula indiretamente à experiência por mediação da diversidade de conceitos do entendimento. Nestas condições é que a idéia atua como fator de unificação e nisto ela corresponde à exigência fundamental do conhecer: unir. Mas, dessas duas unidades citadas, apenas a distributiva é objetiva: isto significa que a razão não prolonga a tarefa do entendimento objetivamente quando acrescenta à unidade distributiva a outra que Kant chama coletiva. A nossa primeira questão, ao mesmo tempo em que é respondida, coloca imediatamente uma outra. Isto é, no mesmo momento em que verificamos que a necessidade de elucidação da idéia - sua função e estatuto - deriva de sua capacidade uni- 
ficadora, verificamos também que a presença da idéia põe em cena uma nova modalidade de unificação. Existe, portanto, um mecanismo transcendental que realiza uma unificação não-objetiva e à qual no entanto Kant chama legítima ou imanente.

Como se configura a legitimidade dessa função unificadora não-objetiva e da qual, provisoriamente, podemos dizer que é imanente a conceitos e não à experiência? O fundamento desta legitimidade é a busca da unidade racional do conhecimento. Unidade racional significa: a maior unidade combinada com a maior extensão; ou a maior diversidade possivel compreendida na mais estrita unidade. A partir disto já podemos avaliar o alcance da Idéia: o entendimento, justamente por se mover no âmbito da experiência possível, exclui do seu alcance a maior diversidade possivel. Esta é apenas o limite ideal do trabalho de sintese. Assim também a unidade, no nivel do entendimento, não é a unidade da totalidade da diversidade mas simplesmente da série accessivel por intuição. Não é portanto a unidade mais "compreensiva". Resta, no entanto, que a unidade relativa, categorial, é a unidade objetiva. Objetividade é igual a segmentação do real. Para além do trabalho do entendimento, a razão configura a unidade maior. Configuraria a "verdadeira unidade"? Seríamos talvez tentados a dizer que sim, opondo à unidade relativa uma unidade absoluta. Mas antes desta conclusão, que seria apressada, convém examinar mais a fundo a função da unidade racional com respeito à realidade daquilo que ela unifica.

Perguntemo-nos então o que significa esta unidade enquanto gênero e o que ela subsume (Nota C). No que diz respeito a conhecimentos efetivamente objetivos, conteúdos objetivos, ou simplesmente objetos, a unidade racional não subsume nada. $\mathrm{O}$ que ela faz é proporcionar às sinteses distributivas o que Kant chama de direção convergente. A convergência não é para mas sim a partir de: numa palavra, a Idéia antecipa a unidade, e uma unidade que não será jamais realmente encontrada, pois o foco irradiador desta unidade se situa fora da experiência possivel e Kant chega mesmo a chamá-lo de imaginário (focus imaginarius). O caráter não teórico das Idéias, o fato de não se referirem diretamente à experiência possível cria uma situação que justifica o nosso propósito inicial de entender o Apêndice da Dialética a partir da relação entre a instância do transcendental e a metafísica. Apesar de não serem condições diretas de objetividade, as Idéias permitem interrogar a natureza na perspectiva da unidade completa e buscar a adequação entre a experiência efetiva e a unidade preconizada na Idéia (Nota D). Como a experiência jamais se adequará realmente à Idéia, o conhecimento, enquanto interrogação da natureza, não é adequado. A razão portanto põe aquilo que ela não pode atingir teoricamente. A relação entre o geral e o particular é naturalmente de subordinação do segundo ao primeiro. Esta subordinação a razão a entende como dedução, o que implica a posição primeiramente do geral para dai derivar o particular. Ora, a partir dos resultados da Analítica, não tenho como pôr o geral na sua maior generalidade: é algo que ultrapassa a experiência possível. O que se pode então fazer sem cair no uso transcendente da Idéia é pôr a unidade não como assertórica mas como problemática ou hipotética. Isto significa que o dinamismo regulador da razão faz uso, em relação à diversidade do entendimento, da possibilidade lógica da unidade racional, a partir do princípio da unidade sistemática da maior diversidade possível.

Sabemos que a experiência enquanto tal também se constitui a partir de possibilidades lógicas: o sistema de princípios e categorias não é outra coisa. Mas, precisamente por se relacionarem com a diversidade sensivel em termos de uma determinação que é também uma restrição, categorias e princípios são constitutivos do conhecimento objetivo. Isto significa que a objetividade se constitui quando, pela síntese, determino o objeto a partir da intuição sensível que é uma apreensão restritiva da realidade em duplo sentido: no da determinação do segmento da experiência no espaço e no tempo; e no da modalidade geral de acesso ao ser, que é a do fenômeno. O modo constitutivo, insistamos, implica restrição, porque a objetividade, ao

Trans/Form/Ação, São Paulo, 11: 1-11, 1988. 
determinar, nega o que está fora das possibilidades de determinação, em cada caso. Ora, segundo Kant, os princípios da razão, que ele em se.

tutivos e sim reguladores. Esta distinção é bem conhecida e é sobre ela que se assentam as relações entre razão e experiência objetiva. Mas, precisamente o que nos interessa aqui é entender a relação constituição/regulação como determinação/indeterminação. $E$ isto exatamente devido ao caráter não restritivo que possui a Idéia da razão, no caso, a idéia que é o princípio ou a máxima da unidade universal. A causa da indeterminação própria da ldéia é que lhe falta a mediação do esquema pelo qual a categoria unifica o diverso sensível (Nota E). A função do esquema é servir de mediação entre a categoria, indeterminada em si mesma, e o sensível intuído com vistas à determinação de um objeto. $O$ esquema restringe a generalidade da categoria e é por via do esquema que se realiza a imanência da categoria ao sensivel. Então, para que os princípios reguladores possam possuir um uso legítimo, o que, repito, significa uso imanente, seria necessário que algo como um esquema da Idéia realizasse a mediação que configura a imanência. Kant fala de um análogo do esquema, que seria a "idéia do máximo (maximum) da divisão e da ligação do conhecimento do entendimento num só princípio".

O princípio de unidade sistemática atua portanto de forma imanente à totalidade da experiência no sentido de concebê-la como a maior e mais perfeita, a totalidade absoluta unificada sob um princípio. Isto significa, respondendo a uma questão que colocamos mais atrás, que o princípio da unidade absoluta não atua como imanente à realidade da experiência, porque não existe para o sujeito totalidade real da experiência. Este princípio atua como imanente à forma da experiência ou à experiência em geral. Trata-se de um dinamismo regulador da razão que faz com que qualquer conhecimento objetivo se insira num todo sistematicamente unificado, contudo indeterminado, já que dessa totalidade está ausente qualquer restrição. A dificuldade que, apenas de passagem, seria preciso assinalar aqui é que esta totalidade deve ser concebida nos termos de completude, o que significaria determinação (Nota F). Isto nos obriga a corrigir a expressão, usada mais acima: esquema da idéia e empregar esta outra: idéia como esquema, entendendo a analogia proposta por Kant num sentido dinâmico, ou seja, a Idéia de unidade sistemática não é dotada de um conteúdo preciso, mas ela é antes a regra da unidade sistemática. Não uma regra que prescreve a unidade sistemática (como, por ex., a categoria de causalidade prescreve a relação causal), mas no sentido de um regra que permite à razão conceber a experiência em sua totalidade como unidade sistemática.

Desta maneira se estabelece uma relação mais nítida entre o princípio da razão e o conhecimento objetivo, que explicita aquilo que mencionamos antes: as Idéias são as condições não objetivas da objetividade. Esta vinculação indireta do estrato transcendental racional ao conhecimento teórico põe o problema do sentido do transcendental a partir da exposição kantiana do Apêndice da Dialética. O que significa, no plano da Analítica, dizer que as condições do conhecimento são transcendentais? Significa, antes de mais nada, deslocar o problema do fundamento. Significa recusar aos princípios do conhecimento o estatuto de realidades ideais e conferir-Ihes o estatuto de idealidades. Em outras palavras, significa retirar dos princípios do conhecimento o peso ontológico que possuiam desde Aristóteles e conferir-Ihes um valor lógicotranscendental, isto é, vincular a operacionalidade das categorias ao uso imanente, renunciando precisamente ao caráter transcendente do fundamento. $\mathrm{O}$ ser, apreendido na modalidade do fenômeno e a partir da constituição lógico-transcendental da objetividade, é dado a um sujeito pré-constituído como subjetividade formal entendida como fundamento suficiente na esfera do conhecimento relativo, no âmbito de validade da certeza concebida a partir das condições do juízo sintético a priori. A metafísica não só é interditada como conhecimento teórico válido, como lhe é recusado também o valor de deter os princípios e os fundamentos do conhecimento.

Trans/Form/Ação, São Paulo, 11: 1-11, 1988. 
Isto significa, do ponto de vista que nos interessa aqui, que a unidade real do conhecimento que espelhava a unidade efetiva, originária e teleológica, do mundo, foi substituída pela unidadę categorial. E, se consultamos a tábua das categorias, lá está, como primeiro conceito puro referente à quantidade, precisamente a categoria unidade. Mas o que transparece no texto do Apêndice da Dialética é que a Crítica necessita elucidar não só a unidade no conhecimento, mas também a unidade do conhecimento. A apreensão do ser e sua determinação objetiva se configuram a partir de um sentido prévio que possui a experiência como um todo e que é a unidade racional. Isto significa que o estatuto genérico das categorias enquanto funções de unidade deve ser pensado a partir de um outro "gênero" racional: a unidade universal. E Kant chama a ambas as unidades: transcendental. As categorias e as Idéias são transcendentais.

A unidade universal pensada na razão corresponde a um interesse da razão. Por isto o princípio de unidade é chamado máxima: máxima é aquilo que transforma um interesse em ação (assim por ex., as máximas do agir no plano da Razão Prática). O interesse, no caso, especulativo, determina a razão a pensar a unidade a partir da sistematicidade e completeza. Mas a unidade não corresponde à realidade, porque real é o que pode ser intuído sensivelmente. Tampouco a unidade racional é aquilo que a categoria de unidade determina como uno. A unidade racional portanto transcende a determinação objetiva de unidade. Ora, as categorias, todas elas funções de unidade, configuram as modalidades de apreensão do ser no plano fenomênico. Às modalidades assim discriminadas Kant chama unidade distributiva, ou seja, unificações relativas ao âmbito de síntese que pode ser realizado por cada categoria. A unidade racional, superior, configura portanto um gênero que permite pensar o ser dado na experiência como unidade sistemática previamente dada, anterior às sínteses unificadoras de cunhio distributivo. Mas, como o que caracteriza a objetividade fenomênica é precisamente a relação categoria-intuição, a modalidade pela qual a razão pensa o ser dado na experiência ćomo totalidade sistematicamente unificada é pré-fenomênica no sentido em que antecede as divisões categoriais pelas quais o ser é apreendido enquanto fenômeno. Ora, a unidade que transcende as definições e divisões do ser é, precisamente, chamada por São Tomás de Aquino: transcendente, e logo por Duns Scot: transcendental. Na filosofia medieval, portanto, unidade transcendental é aquela que transcende todas as divisões do ser (Nota G). Tudo o que é, é um, mas o ser é uno em outro sentido. O mesmo é dizer ser e Um. Assim, a predicação que adiciona ao ser um transcendental como predicado, não adiciona propriamente nada. Toda predicação verdadeira é restritiva, já que definir é especificar. A lembrança do significado medieval do Transcendental não tem o propósito de vincular imediatamente o transcendental kantiano à S. Tomás e Duns Scot. Isto não seria legítimo na medida inclusive em que o próprio Kant, num trecho da C.R.P., repudia as conseqüências, que ele acredita tautológicas, da convertibilidade entre o ser e os transcendentais. Mas, ainda assim, a aproximação serve para nos ajudar a pensar a questão colocada há pouco: em que sentidos as categorias e as idéias podem ser ditas transcendentais? A questão é clara no que concerne às categorias, na medida em que o uso imanente é definido com precisão. Mas no que diz respeito à Idéia de unidade sistemática, a questão se complica pela presença de dois elementos novos: o interesse da razão e a vinculação indireta com a experiênçia. Quando enunciamos a seguinte proposição: "A experiência como um todo é sistematicamente unificada", não dizemos rigorosamente nada em termos de proposição teórica. No entanto, a idéia que esta proposição expressa está por trás de qualquer proposição teórica que possamos enunciar. Isto porque aquela proposição, sem nehum valor teórico, encerra nada menos do que o sentido da experiência. A expressão: experiência possível słgnifica que realizamos experimentalmente as possibilidades dadas na estrutura formal da subjetividade transcendental. Mas o possivel aí não significa a totalização da possibili- 
dade e sim a restrição (determinação) das possibilidades categoriais. As categorias, em si mesmas, excedem as possibilidades concretas de síntese porque não são dimensionadas es-. tritamente em relação à sensibilidade. É o uso legítimo que as dimensiona dessa forma. A idéia de unidade racional preconiza regulativamente a totalização da experiência, não apenas o possivel, mas a completude do passível-de-ser-conhecido. Dar conta da totalidade é um interesse da razão. $O$ interesse da razão só pode ser realizado metafisicamente. $O$ caráter transcendental da Idéia em Kant visa precisamente preservar o interesse da razão sem o retorno à metafísica. Por isto as Idéias transcendentais, no caso a idéia de unidade racional, não têm caráter ontológico mas transcendental no sentido lógico-transcendental. Reencontramos assim o procedimento kantiano que transformou o fundamento ontológico em possibilidades lógicas de objetivação (Nota H). A Idéia é a desontologização do princípio e do fundamento, mas ao mesmo tempo nos indica talvez uma ambigüidade da Dialética Transcendental: a deconstrução da metafísica é ao mesmo tempo a afirmação e a elucidação sistemática do interesse da razão, o que significa de certa forma a preservação daquilo que se quer destruir. $A$ unidade racional como fundamento vazio do sistema da experiência ilustra esta duplicidade.

Exploremos um pouco mais tal duplicidade para tentar extrair conseqüências mais definidas com relação ao problema que nos ocupa. O conhecimento, no nivel da Analítica, se define por possibilidades a priori de unificação. A síntese é a realização dessas possibilidades na exata medida em que é um mecanismo produtor de relações. A Dedução é, neste sentido, a explicitação da forma relacional do conhecimento objetivo. Isto significa que Kant, ao definir o entendimento como órgão de ligação, estabelece ao mesmo tempo em que sentido o conhecimento objetivo é relacional e também a modalidade das relaçð̋es que são efetuadas. Podemos dizer, a partir daí, que a Dedução Transcendental é a reposição do problema do estatuto da relação. A maneira como Kant repõe o problema está na dependência de duas instâncias históricas: a mais próxima se configura no mecanicismo cartesiano e a mais longínqua na maneira como a Escolástica discutiu o problema do ser das relações. No entanto, apesar das diferenças importantes que existem entre essas duas formas de posição do problema, não seria talvez sem propósito dizer-se que elas convergem, de certa maneira, no contexto kantiano em que a questão será recolocada. Isto porque Kant herda de Leibniz as coordenadas em que pensará a questão e, em Leibniz, a presença da questão do ser da relação está determinada pela crítica do mecanicismo estrito de Descartes e por um certo retorno a Aristóteles por via do pensamento escolástico (Nota I).

Do ponto de vista que nos interessa aqui, toda relação pode ser vista como sintese unificadora, uma vez que em Kant, já se viu, categoria é definida como função de unidade. Ora, do ponto de vista do conhecimento físico, o estatuto relacional do conhecimento está, em Leibniz, estreitamente associado ao fenomenismo que define as possibilidades cognitivas neste nível. De modo que, já em Leibniz, conhecer o mundo físico é entendê-lo como sistema de relações. Mas seria amputar a T. do C. de Leibniz não mencionar que tais relações enquanto produtos do conhecimento são válidas na medida em que existe um fundamento transcendental garantindo a objetividade das relações: é o fato de elas serem pensadas por Deus. O estatuto da relação é ser de razão, e, se não houvesse certa comunidade e continuidade entre o intelecto humano e o divino, este ens rationis seria apenas a maneira subjetiva pela qual o entendimento humano une propriedades. A mente de Deus como sede privilegiada das relações confere a elas realidade. Isto, evidentemente, solicita que aceitemos a tese platonizante de que os entes de razão em Deus são reais e é esta realidade transcendente que os torna objetivos quando estão, como entes de razão, em nós. Relações portanto dependem do pensamento, mas dependem originariamente do pensamento de Deus. Podemos ver na concepção leibniziana uma modificação

Trans/Form/Ação, São Paulo, 11: 1-11, 1988. 
do pensamento aristotélico no seguinte sentido: é possivel entrever em Leibniz uma certa recusa do estatuto ontológico que reveste o quadro categorial aristotélico. No entanto podemos entender também a perspectiva de Leibniz em continuidade com Aristóteles: a crítica ao que Aristóteles considerava o substancialismo da Idéia platônica o levou naturalmente a pensar a universalidade em relação à razão, ao Logos (Nota J), ou à maneira como se diz o ser nos vários modos em que pode ser enunciado, uma vez que todos estes modos se remetem a um princípio. A unidade dos modos de ser configura o objeto da ciência do ser enquanto ser. Em que instância se configura o ser como Um? Na instância do Logos. São Tomás dirá, a partir daí, que a unidade tem a ver com a razão, e inclusive definir Deus como Uno só é possível na instância da razão: secundum modum apprehensionis nostrae, ou seja, definindo negativamente a unidade comto o não dividido (Nota L). No entanto, é preciso distinguir a unidade ligada à categoria de quantidade (unidade numérica) da unidade no sentido em que se diz que Deus é Um. Esta última é a unidade transcendental, pré-categorial. A maneira como Leibniz pőe o problema enseja a solução que tenta sintetizar os resultados do mecanicismo cartesiano com o substancialismo aristotélico e tomista. A unidade numérica e estritamente relacional nos dá a conhecer o mundo na sua estrutura física e a físico-matemática tem por objeto o mundo na instância fenomênica pela qual temos acesso ao ser sensivel. A unidade como relações sistematicamente estabelecidas é, portanto, o resultado da ciência. Qual é, no entanto, o estatuto das relações assim estabelecidas? Por que, partindo, de alguma forma, do ser de razão (relação), encontro todavia o ser sensivel na instância fenomênica? Precisamente porque, no limite, a lógica não é senão o real pensado por Deus de forma eminente. Ou seja, não existe efetiva separação entre lógica e ontologia, não porque as categorias lógicas sejam ontológicas, mas porque as relações são, quando pensadas por nós, verdadeiramente reais na medida em que Deus as pensa. Isto significa também que, quando busco as razões de ser do sensivel e dele me afasto na busca do seu fundamento, não perco contato objetivo com o ser, pois além da unidade no nível físico-matemático existe, no nível metafísico, a unidade teleológica assegurada pela harmonia pré-estabelecida. Assim, o caráter ontoteológico do sistema como um todo assegura a coexistência hierarquizada da unidade pensada em diferentes graus do ser.

Isto supõe, como já se viu, continuidade entre lógica e realidade, o que garante não só que o conhecimento continua sendo objetivo quando passo do sensivel ao inteligível, mas ainda que, no nivel do inteligivel, encontro as razões de objetividade do sensível. Ora, Kant recusa esta continuidade em termos de apreensão real de ser, mas não recusa a imanência da lógica ao sensivel. Somente que esta imanência, como já vimos, é configurada como determinaçāo restritiva do real por via da intuição sensível. Significa que as determinações objetivas, asseguradas pelo quadro categorial, propiciarão ao conhecimento de entendimento produzir unidades relativas através da predicação possível pela própria existência das categorias. Do ser, tal como é dado na experiência, se predicam atributos conhecíveis no âmbito categoria/intuição. Se aplicássemos aqui a distinção escotista das formas de predicação, poderíamos dizer que, no nivel categorial, os predicados são enunciados "in quale", isto é, como propriedade e não "in quid" (Nota M), isto é, como essência. Isto ocorre porque não há unidade objetiva real que sustente as 12 possibilidades de predicação. A única unidade a que as categorias remetem para aquém de si mesmas é a unidade formal da apercepção transcendental, que não possui em si mesma nenhum conteúdo. No entanto, existe a afirmação, em Kant, da existência de uma unidade transcendental não categorial que fundamenta a unidade categorial. Esta unidade supra-categorial não nos fornece, como seria o caso em Leibniz, a razão inteligível do ser do sensivel, mas nos indica o fundamento transcendental das unidades distributivas no nivel do entendimento. A universalidade transcendental que assegura a unidade sistemática da experiên-

Trans/Form/Ação, São Paulo, 11: 1-11, 1988. 
cia não é formal no sentido lógico-formal, e sim formal no sentido transcendental, ou seja, sistematiza conteúdos dados. No entanto - e é aqui que vemos de maneira nítida o cruzamento da problemática transcendental com a metafísica - a unidade da Idéia Transcendental sistematiza conteúdos dados sem determiná-los, ou melhor, garante a priori e de maneira indeterminada a unidade da experiência possível, no sentido em que a experiência é busca de uma unidade cujo princípio já está dado pela razão. Isto significa que o ser dado na experiência e distributivamente unificado, está também unificado coletivamente a partir da máxima da unidade transcendental. Isto ocorre sem que possamos, no entanto, predicar a unidade do ser no sentido coletivo, que seria aquele da totalidade da experiência.

Seguindo a distinção escotista que mencionamos há pouco, poderiamos caracterizar esta impossibilidade de predicação como correspondendo ao nivel do "in quid"? A resposta seria sim se pudéssemos, em Kant, inferir a partir da totalidade unificada da experiência a unidade do ser. Mas, ainda que supuséssemos a realização da Idéia Transcendental de unidade, o que teríamós seria a experiência totalmente unificada. A realização total das possibilidades da experiência possivel não anula, no entanto, ao que parece, a separação entre fenômeno e coisa-em-1 si, constitutiva do próprio conhecimento. Isto significa que teríamos, ainda aqui, o ser dado a partir da diversidade original que a intuição só pode apreender de maneira relativa às formas transcendentais. Seguramente não é por outra razão que a Unidade supra-categorial é também transcendental. Ela tem em comum com a unidade categorial a imanência, não à experiência efetiva, mas à totalidade da experiência. $E$ a legitimidade da Idéia deriva precisamente de que ela não tem a ver com a unidade do ser no sentido metafísico, mas com a unidade da experiência do ser tomada em sua totalidade. Ainda assim permanece o fato de que a Idéia de Unidade relaciona-se com o interesse metafísico da razão.

A razão não pode realizar cientificamente este interesse: o resultado da investigação crítica impede que a Metafísica constitua objetos. Predicar a unidade do ser não é possível objetivamente. Se fosse, a metafísica seria, podemos dizer, a ciência dós transcendentais no sentido medieval: o estudo das determinações mais elevadas do ser, entre as quais está a unidade. É assim que ela se define em Duns Scot, para quem a universalidade real é acessível ao conhecimento. E é acessível exatamente porque podemos pensar o ser separado de qualquer determinação e em seguida pensá-lo nas suas determinações mais universais. Ainda mais, o que Duns Scot chama "passiones entis convertibiles cum ente" (unidade, p. ex.) são conceitos unívocos a Deus e às criaturas. É certo que não intuímos a unidade de Deus diretamente, mas constatamos a unidade relativa das criaturas e a partir daí atentamos para a razão formal da unidade, isto é, o que a unidade é em si, independente do ente ao qual se aplica. $A$ razão formal da unidade nos permite então pensar a unidade no nivel transcendente às criaturas, a unidade do ser, a que não temos acesso direto em razão de estarmos condenados ao conhecimento abstrativo. Este procedimento que nos permite chegar aos predicados metafísicos sem intuí-los diretamente deriva de que nosso conhecimento não pode prescindir do sensível. No entanto, se abstraímos corretamente, isto representa a realização de uma potencialidade legítima do intelecto, o próprio caminho da metafísica.

A filosofia crítica evidentemente não pode legitimar a generalização para além do âmbito categorial. Neste sentido ela repõe a dificuldade tradicional relativa à predicação transcendental, mas a repõe numa perspectiva que já encaminha a solução especificamente crítica. Significa que Kant reinterpreta a tese de que os transcendentais só têm sentido no conhecimento (Nota N). No contexto em que é pensada na Filosofia Escolástica, a predicação transcendental nada acrescenta ao ser, mas conhecer o ser é sempre conhecê-lo enquanto uno, belo, bom... Sabemos, no entanto, que esta forma de predicação já representa um descenso do ser para o 
plano da significação, do ser-conhecido. A modificação predicativa do ser se dá no nível da significatividade: o plano da relação entre o ser e o sujeito que o conhece, plano da multiplicidade significativa, é, portanto, diferente do plano do ser. Os predicados do ser somente se acrescentam ao ser no nível do discurso. Isto supõe, no entanto, que o nível do conhecimento está em continuidade descendente em relação ao nível do ser e que o fundamento externo do conhecimento configura a transcendência como pólo diretor da representação. A representação de algo é aquilo que se destaca para nós enquánto este ałgo é, em si mesmo, conhecido. Não há, portanto, qualquer espécie de descontinuidade entre ser e ser conhecido. O conhecimento do ser através da predicação transcendental é modo de conhecimento do ser. Ora, Kant conferiu ao conhecimento objetivo uma natureza tal que o verdadeiramente conhecido é aquilo que pode ser apreendido no âmbito pré-delimitado pela estrutura transcendental (Nota 0). As categorias representam a superação lógica da experiência sensível. Neste sentido elas são aquilo que previamente e desde sempre já pode ser conhecido mesmo antes da apreensão sensível. Somente isto que previamente já pode ser conhecido permanecerá possibilidade formal até que a intuição preencha sensivelmente as formas a priori. Assim, embora mantendo fidelidade ao modo relacional do conhecimento tal como o herda do cartesianismo leibniziano, Kant não pode mais conceber a Lógica como a Realidade eminente: a pré-delimitação que se dá no jogo das faculdades de sentir e de pensar rompe a continuidade entre ser e ser-conhecido, transformando-a numa outra continuidade: aquela que se dá entre o logicamente possível de ser conhecido e o conhecido como "sendo" - deslocação da inversão cartesiana conhecer-se. Assim o transcendental, superando a experiência enquanto configuração dos modos de ser, submete-se, por outro lado, e de certa forma, à experiência sensível, enquanto configuração das possibilidades do aparecer. Mas como o que aparece, determinada e objetivamente, aparece no âmbito de um contexto geral indeterminado e no entanto condicionante, o transcendental é também, e num outro nível, a condição indeterminada do aparecer: a Unidade é a condição indeterminada da unificação enquanto síntese categorial. Não há sobreposição de condições transcendentais precisamente porque a Unidade da Idéia condiciona, na sua totalidade, as possibilidades do aparecer, ao passo que as determinações categoriais condicionam o aparecer na sua determinação particuląr (Nota P). No entanto, existe hierarquia na medida em que a Unidade como indeterminação geral é a condição a priori, desde sempre pensada, de todo aparecer. $O$ interesse da razão consiste em que esta tem, em si, a forma da ontologia, tendendo naturalmente para a produção de conhecimento a partir desta forma transcendental de predicação. Esta tendência repousa no fato de que a ruptura entre ser e ser conhecido se dá no nível da aplicação da razão: a identificação do conhecimento ao que pode ser conhecido (Nota Q) provém do cruzamento das exigências lógicas e sensíveis. Mas, aquém deste ponto de intersecção, a razão guarda em si, na latência da forma, as possibilidades do conhecimento ontológico cuja concretização estaria, doravante, impedida pela descontinuidade que Kant instaura entre o transcendental e o real.

\section{NOTAS}

A - "... a razão humana possui uma inclinação natural para sair dos seus limites, (...) as idéias transcendentais Ihe são tão naturais como as categorias ao entendimento, no entanto com esta diferença que, enquanto estas últimas conduzem à verdade, ou seja, à adequação dos nossos conceitos com o objeto, as primeiras produzem apenas uma simples mas inevitável aparência, cuja ilusão podemos apenas e dificilmente afastar por meio da mais penetrante critica" (6, p. 452-3).

Trans/Form/Ação, São Paulo, 11: 1-11, 1988. 
B - As idéias da razăo năo săo imanentes à experiência porque nenhuma delas "se relaciona jamais diretamente a um objeto, mas simplesmente ao entendimento e, por meio deste, ao seu uso empírico; ela não cria pois conceitos de objetos, mas se limita a ordená-los e lhes fornece a unidade que podem possuir na sua maior extensăo possível, ou seja, em relaçăo à totalidade das séries, totalidade que o entendimento jamais visa, uma vez que só se ocupa do encadeamento pelo qual as séries de condiçōes são sempre constituídas segundo os conceitos" (6, p. 453).

C - "Se lançamos um olhar no conjunto de conhecimentos do nosso entendimento, vemos que a parte que af tem a ver com a razáo ou o que ela busca constituir, é a sistemática do conhecimento, isto é, seu encadeamento em virtude de um princlpio" (6, p. 454).

D - "... interrogamos a natureza (...) a partir dessas idéias e entendemos o nosso conhecimento como defeituoso na medida em que nåo é adequado a elas" (6, p. 454).

E - "Ora, da mesma forma que os atos do entendimento, sem os esquemas da sensibilidade, são indeterminados; também a unidade da razáo, em relação às condiçס̄es sob as quais o entendimento deve unir sistematicamente os conceitos e ao grau em que deve fazé-lo, é, em si mesma, indeterminada" (6, p. 464).

F - "Com efeito, o maior e o absolutamente perfeito podem se conceber de uma maneira determinada, uma vez que todas as condiçōes restritivas, que dão uma diversidade indeteminada, são afastadas" (6, p. 465).

$G$ - $(8,1,11)$. A transcendentalidade da unidade se expressa na forma da convertibilidade entre o ser e o uno, $e$ de resto entre o ser e os outros transcendentais, como o verdadeiro e o bom (Cf. 7, p. 117 ss).

H - "Ora, o que vemos al é somente que a unidade sistemática racional dos diversos conhecimentos do entendimento é um princípio lógico que serve, no caso em que o entendimento não pode chegar sozinho a estabelecer regras, para ajudá-lo por meio de idéias e buscar ao mesmo tempo para a diversidade de suas regras uma unidade fundada num princípio (uma unidade sistemática) e, através disto, uma ligaçāo tão extensa quanto possível" (6, p. 455).

I - (Cf. 7, p. 131).

$J-(1, \Gamma, 21003 b)$.

$\mathrm{L}-(8, \mathrm{I}, \mathrm{XI}, \mathrm{III}, 83-84)$.

$M$ - $(2, \mathrm{l}$, distinção 3, parte I, 334).

O universal lógico é um conteúdo de razão, para Duns Scot. Ele é predicável da pluralidade na medida em que o multis se remete ao unum. Enquanto trata dessas possibilidades de predicação, a lógica é completamente distinta da metaffsica. No entanto, não existe qualquer impossibilidade constitutiva para que aquilo que está fora do pensamento do ens reale, esteja ou venha a estar no pensamento como ens rationis; o intelecto possui virtualidades que vão inclusive arém do conhecimento abstrativo. Pode-se dizer, por exemplo, que o unum está de alguma maneira in multis, só que é o metaflsico que deve mostrar como esta relação de predicação se realiza. Deve-se observar também que Duns Scot considera o ens commune como real, 'o que significa que o conhecimento pode atingir a comunidade que é a universalidade real. Por isto a Metafísica é ciência do real, próxima da Fisica e distante, se bem que não irredutivelmente separada, da Lógica (Cf. 4, p. 106, 108).

$N$ - (Cf. 3, p. 155).

"Les trancendentaux, dont nous avons dit qu'ils s'offrent à la pensée dès qu'elle pense l'être, posent des problèmes différents. Assurément, ils sont convertibles avec l'être, mais ils ne sont pas l'être en tant que tel. Chacun d'eux signifie l'être en tant q'un on vrai, on bon, on beau. On ne peut donc les concevoir sans l'être, mais ne peut'on concevoir l'être sans eux? On ne peut le concevoir d'aucune manière sans mettre en cause l'un, le vrai et le reste, mais c'est qu'alors il ne s'agit plus de l'être en tant qu'être, mais de l'être en tant que connu."

O - Ou seja, Kant pensou a adaequatio no sentido de uma adequação das coisas ao intelecto, na medida em que este já dispõe da estrutura transcendental do aparecer. (Cf. 5, p. 83; Cf. 7, prefácio da 2ª Edição).

$P$ - As possibilidades do aparecer em geral estão ligadas à possibilidade de conhecimento efetivo da universalidade real: quais são, neste sentido, as condiçōes reais de apreensão no nível do ens commune? É o problema da fundamentação da Metaffsica, do qual é subsidiário o problema da legitimação quid juris da ciência newtoniana (Cf. 5, p. 72).

Q - No Prefácio da 2 $2^{\text {a }}$ ed. da C. R. P. Kant fala da Crítica como da "preparação necessária para o desenvolvimento de uma metafísica bem estabelecida (...)" e fala também da Metaflsica como "execução do plano que traça a Crfíca" (Cf. 6, p. 26 e 6, 76). 
SILVA, F. L. e - The metaphysics in the critique of pure reason. Trans/Form/Ação, São Paulo, 11: 1-11, 1988.

ABSTRACT: This paper discuss the relations between the transcendental analysis of Kantian's Ideas of Reason (specially the Idea of Unity) and the traditional Metaphysical heritage. We try to understand the first Part of the Apendix Transcendental Dialectics under the light of critical remaking of the metaphysical themes, with special accent on the scholastic notion of "T ranscendental atribute of Being".

KEY-WORDS: Critic; metaphysic; transcendental; unity; logic; ontology.

\section{REFERÊNCIAS BIBLIOGRÁFICAS}

1. ARISTOTE - La métaphysique. Paris, Vrin, 1970.

2. DUNS SCOT, J. - Opus Oxoniense. São Paulo, Abril, 1973. (Coleção Os Pensadores).

3. GILSON, E. - Conaissance des trancendentaux. In: Constantes philosophiques de l'être. Paris, Vrin, 1983.

4. GILSON, E. - Duns Scot, introduction à ses positions fondamentales. Paris Vrin, 1952.

5. HEIDEGGER, M. - Kant et le problème de la métaphysique. Trad. de A. Waelhens e W. Biemel. Paris, Galimard, 1953.

6. KANT, E. - Critique de la raison pure. Trad. de Tremesaigues e Pacaud. Paris, PUF, 1975.

7. MARTIN, G. - Science moderne et ontologie traditionelle chez Kant. Paris, PUF, 1963.

8. TOMÁS DE AQUINO, Santo - Summa Theologica. Trad. de Alexandre Correa. Caxias do Sul, Univ. de Caxias do Sul, 1963. 